\title{
The Research Journal Club: Pedagogy of Research in the Preparation of Students in Educational Leadership ${ }^{1}$
}

\author{
Alex J. Bowers ${ }^{2,3}$ \& Elizabeth Murakami-Ramalho ${ }^{3,4}$
}

\begin{abstract}
Following calls to increase professional communities of practice around research in educational leadership graduate programs, this study describes the ongoing process of creating a research journal club. We share the process of implementation, describe the structure adopted, and the outcomes observed one year after the establishment of a journal club. Through involving graduate students with faculty in bi-monthly conversations about recent research articles, participants engaged in intellectual risk-taking through discussing high quality research. This study highlights the importance of establishing a space to model scholarly research debates, bringing together faculty and students in a community of research practice.
\end{abstract}

Keywords: Leadership preparation, Journal club, Communities of practice, Graduate student

\section{INTRODUCTION}

\begin{abstract}
"The urgency of the need to improve the practice of education may well serve to strengthen the kinds of professional communities of inquiry that can make us (and our doctoral students) better researchers." (Young, 2001, p.5)
\end{abstract}

Graduate programs in education, and educational leadership and administration specifically, have undergone a recent wave of critiques (Hess \& Kelly, 2005; Levine, 2005) in relation to the rigor, content, and relevancy of preparation programs in the United States. These critiques have focused on a lack of connection between graduate program curriculum and the daily work of educational leaders in schools, lax graduation standards, a disconnect between faculty research and principal and superintendent needs, inadequate field experiences, and questions regarding the quality of research conducted by faculty and graduate students. While problematic in many respects, these critiques initiated a spearheaded response from the UCEA/TEASIG Taskforce on Educational Leadership Preparation, which has been attentively assessing educational leadership programs and

\footnotetext{
${ }^{1}$ This document is a pre-print of this manuscript, published in the Journal of Research on Leadership Education in 2010. Recommended citation: Bowers, A.J., Murakami-Ramalho, E. (2010) The Research Journal Club: Pedagogy of Research in the Preparation of Students in Educational Leadership. Journal of Research on Leadership Education, 5(10), 335-356.

doi:10.1177/194277511000501001

${ }^{2}$ Teachers College, Columbia University; Bowers@tc.edu; 525

W. $120^{\text {th }}$ Street, New York, New York 10027.

ORCID: 0000-0002-5140-6428, ResearcherID: C-1557-2013

${ }^{3}$ Formerly at The University of Texas at San Antonio at the time of publication.

${ }^{4}$ The University of Texas Permian Basin

Note: This document last updated September 4, 2013
}

working to identify areas of improvement (Black \& Murtadha, 2007; Young, Orr, Crow, \& Ogawa, 2005).

One area nominated for improvement has been the teaching and learning of research through both formal and informal opportunities in graduate programs. Educational leadership and administration professors have been challenged to engage in deeper conversations with graduate students about the usefulness and practice of research, to discuss their own learning and engagement in educational research, and to privilege the voices of graduate students as learners and future experts in the practice of educational leadership (Silverberg \& Kottkamp, 2006). However, as opposed to other research-oriented graduate degrees (Golde \& Walker, 2006; Walker, Golde, Jones, Bueschel, \& Hutchings, 2008), a recent study indicated that while modeling and teaching graduate students to assess and perform high quality research, students will learn how to do research only when they are actively involved in a research project (Golde, 2007b). In educational leadership programs in particular, there is concern that many graduate students are working practitioners and therefore their engagement in research is limited, especially considering that these professionals are often commuters and part-time students.

The purpose of this study is to examine the first year of the implementation of a research journal club in a department of educational leadership of a large four-year, primarily nonresidential, doctoral, professions dominant, public university (Carnegie Foundation Classifications, 2007). Contrary to Levine's (2005) perception that educational leadership professionals do not need to engage in research unless they enter the professoriate, we believe that research should be developed even earlier in graduate programs (both at the masters and graduate levels) to improve the quality of school administrators and academics and consequently improve of the field of education.

Recently, as part of a larger study by the Carnegie Foundation on U.S. graduate programs across multiple disciplines, Golde and Walker (2006) called our attention to the fact that different fields socialize graduate students differently into research and scholarly enterprises. Journal clubs and reading lists are a type of activity these scholars observed that were well developed in fields such as English, literature studies, and the natural sciences, but were absent in fields such as education (Golde, 2007a). As significant informal interactions in graduate education (Cronon, 2006), as well as a way to develop professional identity (Lave \& Wenger, 1991), research journal clubs help graduate students find and build a place within a community of researchers. However, journal clubs have not been traditionally part of the induction of graduate students in the field of education. Even though the importance of journal clubs and the way they can be instituted in educational graduate student and faculty programs has been posed, along with recommendations for implementation (Golde, 2007a), research to date on instituting journal clubs in education graduate programs is insufficient. Given the call to include these types of activities in colleges of education, we were interested in 
observing how the alignment between the goals of a journal club and the goals of improving educational leadership graduate programs could improve the research knowledge of graduate students and faculty in this field.

The central purpose of a journal club is to encourage intellectual risk-taking and dialogue between graduate students and faculty around research in a professional community of practice. In addition, journal clubs have three additional goals. First, everyone in the department, from senior faculty to entry-level graduate students, is able to use a journal club to keep up with the literature. Second, journal clubs teach and model the protocols and norms of evaluating and communicating research findings as well as how to ask and address publishable and applicable research questions. Third, through these conversations, journal clubs encourage the establishment of connections across faculty, students, mentors and peers, fostering professional community within the department, college, students, and community.

In this study we share the process of implementation, describe the structure adopted, and describe the outcomes observed one year after the establishment of a journal club in a research-oriented department of educational leadership following the established guidelines from the journal club literature. We describe the first year progress of the journal club to understand the value of the process for educational leadership graduate students and faculty to initiate and improve the signature pedagogies in the profession. Our aim was to a) understand how journal clubs, as traditionally conceived, may be adapted for educational leadership graduate programs given the scarcity of full-time students in educational leadership and $b$ ) address the traditional insulation of faculty in graduate research.

\section{REVIEW OF LITERATURE}

\section{Communities of Practice and Signature Pedagogies}

It is well known that for much of graduate student training, research methods are presented in separate classes and forums, which are in many ways divorced from practice and application (Berliner, 2006; Page, 2001). Much of the literature on graduate training in education argues for the integration of high quality research with real-world application. Academically, it argues for current and actionable findings throughout a graduate student's career, exposing and engaging graduate students to multiple paradigms, epistemologies, and ways of knowing (Black \& Murtadha, 2007; Mertz, 2001; Young, 2001).

However, it has been noted that confronting multiple and sometimes conflicting epistemologies and ways of knowing in educational research is a difficult process for many graduate students and faculty, resulting in exasperation, anger, self-doubt, and a sense of disengagement from the student's past to the demands of research (Lesko, Simmons, Quarshie, \& Newton 2008; Mertz, 2001; Page, 2001; Young, 2001). These observations indicate that courses and pro-seminars for doctoral students, for example, have as their central goal the exposure and engagement of students in a diverse set of epistemologies and ways of knowing in educational research. However, these courses do not foster a collaborative and community building spirit from graduate students.

These types of courses have been identified by students as a valuable experience that expanded their conceptions of what is research in education and how they might think in multiple ways about a research project. However, in the end, these courses generally are something to "get through" or "endure" as evidenced by the language used to describe the students' experiences - such as "monstrous," "border crossing," and "dreadful" (Lesko et al., 2008; Mertz, 2001). As noted by a student in Mertz's (2001) study of doctoral students in a proseminar on educational research methods:

There were definitely times when I dreaded the seminar and joked with other students that if I had to deal with one more existential funk brought on by our discussions of ontology and epistemology, I was sure that my mind was going to snap. (p.15)

On the other hand, limited and restricted exposure of graduate students in education to research methods are counter to the call to improve educational graduate programs and research (Berliner, 2006; Lesko et al., 2008; Page, 2001). This is especially true as programs have been urged to require that both graduate students and faculty be actively engaging in collaboration, modeling high quality research, and enhancing dialogue between and within faculty and students in an effort to promote positive communities of practice and support the development of knowledge and skills around research (Murphy, 2006; Tierney, 2006).

\section{Communities of Educational Research Practice}

Supportive faculty and graduate student interaction has come to be known as a community of educational research practice (Pallas, 2001) based on the communities of practice literature (Lave \& Wenger, 1991; Wenger, 1998). As described by Pallas (2001), a community of educational research practice serves four concurrent purposes. First, through participation in a formally organized community (here considered to be organized around improving educational research), members create meaning through participation and reification. Participation involves active engagement in the community to create a sense of shared meaning, while reification involves the generation of formal and useful artifacts (i.e., documents, practice guides, summaries, schedules, and reports) that record and "reify" the work of the community and are used by members to further their goals and the goals of the community. Second, the community enhances meaning-making by ascribing "agency to newcomers, and [seeing] generational encounters between newcomers and oldtimers as opportunities for community learning and the development of changed practices" (Pallas, 2001, p.7). Third, through "mutual engagement" members increase their interaction, gain personal access to the deeply held knowledge and practices, and hold each other accountable for future work. Through these interactions, students learn how to evaluate each other's work more critically, and access the locally constructed resources of the group for future work. Fourth, as argued by Pallas (2001), many university faculties of education are in communities of practice when fulfilling teaching obligations, administrative processes, and overseeing the matriculation of students and the machinations of the tenure process. An alternative conception is that faculty work should shift from this type of administrative community to a community of educational research practice. Each faculty member should work together with graduate students and the rest of the faculty to create a broader community focused on improving educational research - by engaging in dialogue and critique of multiple and competing research epistemologies (Pallas, 2001; Young, 2001). In the end, the call for communities of educational research practice encourages faculty to engage in the process of bringing the practice of educational research to the fore in discussions with not only graduate students, but other 
faculty around them who may hold diverse and conflicting concepts of "educational research."

\section{Signature Pedagogies}

An increased focus on building communities of educational researchers has led faculty to nominate structures and processes that can aid in helping to build such communities. These issues have led to the examination of the "signature pedagogies" of graduate programs and educational leadership graduate programs (Black \& Murtadha, 2007; Shulman, 2005). As defined by Shulman, signature pedagogies "implicitly define what counts as knowledge in a field and how things become known. They define how knowledge is analyzed, criticized, accepted, or discarded" (Shulman, 2005, p.54). Types of signature pedagogies discussed by Shulman include case study in law courses and bedside teaching with clinical rounds in the medical field. These pedagogies all share certain commonalities, which include a focus on the knowledge of the discipline, application of that knowledge, public student performance, and a persistent and replicated routine or habit. Shulman acknowledges that habit can lead to complacency. However, the following quote sums up his central point about the habit and routine of signature pedagogies:

To put it simply, signature pedagogies simplify the dauntingly complex challenges of professional education because once they are learned and internalized, we don't have to think about them; we can think with them... Habit makes novelty tolerable and surprise sufferable. The well-mastered habit shifts new learning into our zones of proximal development, transforming the impossible into the merely difficult (Shulman, 2005, p.56).

In this way, signature pedagogies provide a scaffold upon which the difficult work of meaning-making allows participants to focus on the content and question at hand, privileges student voices, and encourages new learning in a supportive yet rigorous environment.

This conception of signature pedagogies appears to address many of the issues noted above in educational research preparation and the call for communities of educational research. A signature pedagogy in educational research preparation designed to create routines to support intellectual risk-taking would be beneficial, especially if it decreases the anxiety graduate students report when it comes to research methods. It also allows for collaboration and community-building among and between faculty and graduate students around high quality discussions in educational research.

\section{The Journal Club as Signature Pedagogy}

Observing and applying Shulman's recommendations for a signature pedagogy, Golde (2007a) nominated journal clubs as one type of signature pedagogy that should be included in graduate programs in education in order to address many of these issues. According to Golde, journal clubs are a

...formally organized reading group that discuss an article found in the recent research journals. A single article is at the heart of each journal club presentation and discussion.... Journal clubs are conventionally multigenerational; they include faculty members, postdoctoral fellows, advanced graduate students and novice graduate students as equal participants. (p.345)
As further articulated by Golde (2007a), research journal clubs serve three main purposes. First, all participants, from junior to senior faculty, and from new to senior graduate students, are able to stay abreast of the current research literature, providing a "collective effort to promote awareness of current research findings" (p.346). Second, the methods and established protocols for presenting, critiquing, and evaluating research are modeled and practiced in a semi-public forum: faculty model and students practice the skills required to present the research findings of others, facilitate a research-oriented discussion, and engage in an open yet rigorous debate in which "students learn to ask good questions, to respond to questions, and to disagree with otherseven professors" (p.346). Third, journal clubs can cross disciplinary and organizational boundaries, including different faculty and graduate students from across a domain, department, or school, so "when people come together, the resulting conversations can build bridges and establish trust" (p.346).

Overall, the research journal club provides an open forum for faculty and graduate students to (a) discuss current research, (b) model the skills needed to understand and apply high quality research and research evaluation, and (c) provide access to multiple scholars across discipline areas and levels of experience and expertise. In addition, the research journal club provides an interesting avenue to address many of the critiques around the research preparation of graduate students in educational leadership programs.

The research journal club is an attractive concept in educational leadership and administration for three main reasons. First, research journal clubs in colleges of education help both graduate students and faculty to examine recent and current literature that may cross many of the epistemological boundaries, including the qualitative and quantitative divide (Eckardt, 2007; Ercikan \& Roth, 2006). These examinations encourage dialogue and engage faculty and graduate students in a deeper discussion of research methods and ways of knowing. Second, research journal clubs provide a more open and friendly forum as an alternative approach to formal classes, providing students and faculty with an environment that encourages intellectual risk taking. Third, as a community of educational research practice, research journal clubs can also serve to build community and allow students and faculty to identify research collaborators, advisors, and committee members as a community of practice. Rather than focusing solely on the single-course experience, education programs could establish a community of persistent educational research practices organized around the routines of a research journal club.

Research journal clubs expand and support rigorous research and model a culture of evaluation and critique of recent research findings that students and faculty can continually return to, helping to improve their skills and networks. Given this combined conception of the research journal club as addressing many of the critiques around educational leadership research preparation, the purpose of this study is to examine the first year of the implementation of a research journal club in a department of educational leadership. The department's goal was to improve graduate student and faculty opportunities and experiences in research while also establishing a routine around evaluation and discussion of current research in education. While a discussion of a single year of implementation is insufficient to warrant an argument that journal clubs improve the research experiences of graduate students and faculty, our aim with this study was to research the development and sustainability of a journal club in a department of educational leadership. 


\section{METHODOLOGY}

This study describes the establishment of a journal club in a research-oriented department of educational leadership at a large research university in the south central United States. The overarching question for this research was to describe how journal clubs may be adopted and adapted as a means to serve students in educational leadership graduate programs given the scarcity of full-time students in educational leadership, and the traditional insulation of faculty in graduate research. The first year of implementation was observed using an intrinsic qualitative case design (Creswell, 2005; Stake, 1995, 2005; Yin, 2003) and descriptive analysis. In an intrinsic qualitative case design, the researchers define the case as a bounded system and the object of the study. Therefore, the case is "the product of the inquiry" (Creswell, Hanson, Clark, V.L.P., \& Morales, 2007). Rather than looking at individuals and their stories, we relied on multiple sources of data to build an in-depth contextual understanding of the research journal club as a signature pedagogy that models and teaches graduate students about ways to assess and analyze high-quality research.

\section{Data Sources}

The university is a large four-year, primarily non-residential, doctoral, professions dominant public university (Carnegie Foundation Classifications, 2007) located in a major metropolitan area and serving an overall student population of approximately 30,000. The department of educational leadership and policy studies is located within a college of education with 19 tenure track faculty members, serving over 250 masters' students, and over 50 doctoral students. The vast majority of students are parttime (or commuter) who hold teaching or administrative positions in surrounding school districts.

The department of educational leadership pioneered the implementation of a journal club following Golde's (2007a) recommendations of establishing a journal club in a college of education. Four main issues were considered in its implementation: First, two faculty members (the authors) were assigned to help implement the club. Second, mandatory attendance was required from a small core of masters and doctoral graduate research assistants in the department $(n=7)$ who would consistently coordinate and attend the meetings. These students were provided two hours of paid time per month to implement and conduct the meetings. Third, the department chair, as well as the dean of the college, provided snacks and demonstrated their support at the meetings. And lastly, scheduling and organization of the meetings was coordinated by the doctoral students, who scheduled two meetings a month, every other week, one in the morning, one in the afternoon.

The journal club activities were observed for two semesters, with the researchers attending all 16 planning meetings and 14 journal club meetings. Interviews, direct observations, participant observations, archival records, and documents were collected. Direct observations were performed through the researchers' attendance. Archival records and documents included the student governing group's meeting minutes, flyers, announcements sent out to invite students to attend, and articles selected for presentation. Individual semi-structured interviews were collected from10 faculty members (by email) who were familiar with or had participated in sessions, and 6 students (face-to-face) who participated in the journal club (the core of masters and doctoral graduate research assistants minus one doctoral student out of the $n=7$ who resigned from the assistantship position soon after implementation). The student and faculty members who did not participate in the journal club were approached for interviews, but all declined to participate in the study. Face-to-face interviews were tape-recorded and transcribed verbatim. Email questionnaires were followed-up with member-checks. Interview questions for students explored:

a. Their expectations and the required level of participation during journal club meetings;

b. The support or guidance they received to attend, participate, and present at journal club;

c. Their confidence in speaking during the journal club; their thoughts on the types of articles presented;

d. The structure, dates and times of the meetings; the sense of community among graduate students and faculty within and outside the journal club;

e. The perceived norms and goals of the journal club;

f. The perception of the support for the journal club, and

g. How the journal club may or may not help them in their career.

Interview questions for faculty explored:

a. The effectiveness of dates and times of the meetings (two meetings per month-once in the morning, and once in the afternoon);

b. Perceptions of the structure of the meetings;

c. Thoughts about the types of articles presented;

d. Community-building expectations among graduate students and faculty through venues such as the research journal club;

e. The general atmosphere of the sessions;

f. The perceptions of the support for the research journal club including students, faculty, chair, and the dean of the college;

g. The participation of graduate students versus faculty members in the club's discussions;

h. How can the research journal club be useful to faculty members, and

i. Implications for educational leadership graduate preparation programs.

\section{Analysis and Findings}

The data sources informing the case were further developed through a descriptive analysis. Considering that in a qualitative analysis, describing, analyzing, and interpreting data are not mutually exclusive (Merriam, 2002; Miles \& Huberman, 1994), we analyzed the data through a "careful, systematic way, identify[ing] key factors and the relationship among them" (Wolcott, 1996, p. 10). Archival records, direct observations, and documents were analyzed to reveal the evolving structure of the sessions. The students' and faculty responses were analyzed separately. Both student and faculty responses were rich in providing their perspectives of the research journal club. Even though faculty responses were given by email, the responses were reflective and descriptive of their experiences. Member-checks for additional information were sought to further inform the researchers. The researchers then clustered the data as to accurately describe the chronology of events, sorting the data based on (a) the implementation process, (b) the established structure, and (c) outcomes as communicated by the participants, and through researchers' observations. The findings include emic data, followed by the researchers' interpretation and negotiation of the data (etic data) (Creswell, 2002), with the aim of increasing our understanding and knowledge base of journal clubs as conducive communities of practice environments for graduate students' development of research knowledge. 


\section{Ethical Considerations and Limitations}

As mentioned, a single year of implementation by the authors combined with a small sample may not be sufficient to build an argument about journal clubs as improving the research experiences of graduate students and faculty. Nonetheless, this initiative is perceived as a starting point to the development and observation of alternative and semi-structured activities that familiarize both masters and doctoral students to the craft of research. As the proponents of the research journal club, we were heavily involved in the initiative. It was important that we recognized possible biases that may have occurred in the development and analysis of this research. Biases were carefully observed and treated in the development of this study, with the performance of department faculty and research journal club member-checks in order to accurately disseminate the findings.

\section{RESULTS}

\section{The Journal Club Implementation}

The journal club was initially proposed by two faculty members at a faculty meeting of the department of educational leadership. The proposal was unanimously supported by both the faculty and the department chair. Following the approval to implement the journal club, the department chair invited the graduate and research assistants (masters and doctoral students) at the beginning of the year to prepare them to include the journal club as part of their assistantships.

Two faculty members volunteered to be the advisors for the first two years of implementation. A follow up meeting with graduate and research assistants was held with the advisors to establish a governance structure. Students voted on the distribution of roles and defined the necessary personnel among the members of the group who would take the responsibilities as the journal club general coordinator (responsible for recruiting presenters and coordinating operations), communications coordinator (responsible for advertising the club), facilities coordinator (responsible for securing a meeting room), a technology coordinator (responsible for the presentation equipment), and refreshments coordinator (responsible for securing funds and providing the refreshments). Additional roles included a student responsible for taking minutes during the club sessions, and a student responsible for distributing and collecting a feedback survey at the end of the session. These roles were defined for oneyear terms.

Following Golde's (2007a) suggestions for the implementation of the journal club, three main factors were noted as important to maintain the journal club: mandatory attendance for a small subgroup, provision of food at the meetings, and the perception that the journal club is of educational value by the program director and the college dean. These same three factors appeared to be helping sustain the initial efforts of implementing the journal club. First, with the support of the department chair, mandatory attendance was created by shifting two hours a month of each of the department's six full-time graduate research assistants' paid time to attending the journal club. When asked about the leadership role the graduate students were taking, one of the respondents said:

It's our journal club. It's not Dr. So-and-so's. [The graduate students] are coordinating. It's the department working for the students. It's their journal club... Everybody picked up a little bit of a task that they're responsible for doing, and that helps with the leadership to really make [the graduate students] understand that they're all [working] as a team of leaders.

Unlike a class or a seminar which would be run by a faculty member, the journal club was perceived as collectively organized and facilitated by graduate students.

Secondly, the implementation aligned well with the literature on journal clubs in that the dean provided funds for snacks at the meeting, such as cookies and drinks. This may seem trivial and an unnecessary cost; however, respondents indicated that food provided by the college indicated support of the journal club from the department and administration and also helped create a more informal atmosphere, different from a classroom. One of the students replied:

Food does tend to relax the mood a little bit... I think it's good to have it. It wakes everybody up a little. It gives people time at the beginning to speak with one another and I think the conversation at the beginning when they're eating is more of a sitting back and listening to the early discussion and then once you're finished with your food, then that's when the conversation should really shift to more debate.

As suggested in the literature on successful journal clubs, (Alguire, 1998; Golde, 2007a), the provision of food at the meetings appeared to help reinforce the structure of the meetings, bringing participants into the meeting, and creating a more informal structure.

The third aspect of a sustained journal club is the support of the chair of the department. As noted above, the chair demonstrated support for the journal club through providing food at the meetings as well as requiring and paying for the attendance of graduate students. In addition, the chair attended many of the meetings and presented an article. As noted by a faculty member, "[the chair] has been very supportive of this effort by requiring graduate assistants to attend and providing refreshments."

The meetings were scheduled regularly for one hour per meeting, and there were two meetings a month (Tuesday mornings and Thursday afternoons, prior to evening classes). Both faculty and graduate students were invited to attend via email and through flyers posted around the college. Rotating every other meeting, either a graduate student or faculty member presented a single peer-reviewed research article (of their choosing) published in the last three years for twenty to thirty minutes in which they:

Summarize the article. Locate it in the larger landscape of the field. Describe the [research] in sufficient detail that the audience can understand it without becoming overly wrapped up in the details. Explain why the article is important. Critique the article: Do the data and their analysis withstand scrutiny? Are there contradictions or competing hypotheses? The discussion focuses on the big picture: the article's strengths and weaknesses, how the article extends the field, potential applications of the work, and what questions need to be answered in light of the current findings. (Golde, 2007a, p.346) 
The presenter received guidelines for the journal club presentation that included the purpose, goals, and objectives of the journal club, and the requirement of using current articles not authored by the presenter. The presenter was asked to email the article to the journal club coordinator a week earlier so that attendees were able to read the article and come prepared to join the conversation. After the presentation, the presenter then facilitated a discussion of the article for 40 minutes, further elaborating on the issues presented on the strengths and weakness of the article, and how it either fit or did not fit into the broader landscape of the field.

Surveys were distributed at the end of each session to invite participants to share whether the session was informative and if the session was helpful in their graduate studies. The governing group met once a month to examine the surveys and make necessary adjustments to improve the sessions and plan subsequent sessions. Over the course of the first year, attendance at the meetings consisted initially of three to four faculty members and five to six graduate students, but grew to include up to six faculty members and fifteen graduate students. This increase in attendance and continued persistence of the meetings aligned with the past research on successful journal clubs that had been sustained over multiple years and had attracted a large audience of both graduate students and faculty (Alguire, 1998; Golde, 2007a).

After the first year of implementation, and through following the recommendations of the journal club literature, it appears that the journal club was beginning to attract a larger audience. With the support of the chair, the graduate students and faculty appeared to view the journal club as a valuable opportunity that was supported and encouraged by the department. It is hard to imagine the journal club persisting without such active and demonstrated support.

\section{Students' Perceptions}

Students in the department of educational leadership were not traditionally prepared to be part of academic activities. Even though the college routinely invited guest speakers to present important topics in education, students in the department of leadership rarely attended. Nonetheless, students in the journal club often invited their colleagues, and as a consequence, increased the participation of students in the journal club. Students were initially apprehensive to take a stance on issues, but later in the year, they seemed more comfortable participating in the discussions. The challenge for students was to take risks voicing their opinion, especially in front of professors, and most importantly, to present in front of the students and faculty. Students perceived value in both the presentation of recent research as well as the discussion among graduate students and professors that followed the presentation of the research article:

I think [the journal club] is useful because you're exposed to more articles, more topics, more research, but also, if I can listen to my professors and how they're arguing points or referencing people I think that that can help my writing, and my research, and just how I approach the doctoral program.

A student who presented at one of the sessions added:

If there is any one great impact to me, it is the fact that I have had this exposure on how you present research, and I said, oh, that's the way you do it. Honestly, I haven't done this before...I learned a lot in terms of how you go about the presentation, which is entirely different from class presentations, having different kinds of perspectives in presenting different kinds of papers.

For beginning students, the most important aspect of the journal club was access to professors and their research agendas. As one student observed,

I got a chance to really know the faculty members and what their research interests were, even if [that] professor [was] not presenting. You pick up about some of the things they like, or that they have an interest in. If they are presenting, you get a good idea about what their perspectives are, whether they study qualitative research or quantitative. You get a chance to see the perspectives they come from and how to not be as intimidated... [you] get a chance to see a whole different side of the professors.

One of the aims of the journal club was, in fact, to encourage intellectual risk-taking by the graduate students as they engaged in conversations with professors centered around research methods and findings. This type of intellectual risk-taking was evidenced in the data collected. Even though students felt rather intimidated, the journal club modeled ways to become more articulate and critical of the articles under discussion. As evidence of this, one student noted that:

It is very interesting to see how people start discussing the article with different points of view... I have never had a chance to participate in anything like that-it is very interesting to listen to different professors that teach different courses with different points of viewand students also, giving their views on the articles. It is teaching me how to see things inside the articles that I could not see before. I was looking at the articles, and I could not see what I see now.

This student's comments demonstrate that for many students, the journal club provided an additional opportunity that, rather than duplicating course work, helped deepen the student's ability to analyze and critically assess research.

When asked about conversation flow in the journal club, a graduate student responded that she enjoyed how she could ask and provide her opinion during the meetings:

"Hey, Dr. So-and-so, what do you really think about this particular concept they're presenting here,"' and then get that person's perspective, and in a lot of cases, you may get somebody who completely disagrees with that to step forward and say, "Hey, I like that, but this is what I think on the other end."

One of the doctoral students reminded us that the journal club allowed her to meet other students on an informal basis, helping her connect with other graduate students: "You get a chance to meet more people, which extends that professional learning community." She added:

The journal club is bridging the cohorts. I met someone from [the cohort two years in front of me], as well as from [five different cohorts] and we have some of the same research interests. All of that comes as a 
part of the articles [presented] because if it is an article that you are speaking on-that is the area of interest in your research study and another person immediately is going to say, "Hey, I'm studying this too!"

Overall, the graduate students reported that the content of conversations was informative between professors and graduate students. There were occasions in which students were uncomfortable with the interactions. When faculty dominated the conversations, for example, students tended to retract from voicing their opinions. However, these were also learning opportunities and significant to belonging to a community of practice.

\section{Faculty Perceptions}

Faculty attending the journal club sessions perceived students as benefitting from the process of becoming familiar with research outside of structured courses: "The journal club seems to be providing supplemental reading for graduate students that they probably would not be exposed to in their class." Another faculty member noted that the journal club provided additional opportunities beyond the department's doctoral research methods course by helping students to:

Develop skills related to: (a) evaluating the present context of research in education including the credibility of educational research, research-based evidence in education and the usefulness of research in education; (b) understanding, critically assessing, and analyzing educational research, and (c) evaluating the characteristics, strengths, and weaknesses of the major qualitative and quantitative research approaches.

One of the research journal club's purposes was to facilitate students and faculty in conversations centered on the diverse set of epistemologies present throughout educational research. One faculty member stated, "when I can attend [the journal club], it's very useful and fun. It gives me a chance to discuss current research with colleagues and graduate students." The sessions seemed to be informative to faculty as well. A faculty member perceived the journal club as "an important initiative to socialize doctoral students into the climate of scholarship within the academy. It is an extension of coursework that keeps the conversation going." Another member noted that "in terms of usefulness, most of the articles I've seen presented are ones I was already familiar with. I believe the value lies in the discussion of the article."

The majority of faculty members were attending morning sessions as opposed to afternoon sessions due to their need to prepare for class in the afternoons. In turn, afternoon sessions were more viable to commuter students since they often attended class after the journal club. Time conflicts therefore influenced the atmosphere of the conversations. A faculty member reflected:

It seems that each meeting has a slightly different atmosphere, depending on who attends the meetings and who is presenting (faculty or student)... At this point, the journal club still feels like a meeting driven by faculty, which causes a slight tension in the meetings.

In effect, faculty tended to talk more in the initial meetings. With time, faculty members participating more frequently noticed the uneven participation in the discussions and were more sensitive to offering their input, as confirmed by one faculty member who added, "I have noticed that students seem a little more assertive about their participation and their interaction with faculty. This is a good way to build relationships."

\section{The Choice of Articles and the Value of the Discussions}

An important feature of the journal club format was the choice of articles presented. The articles varied from empirical research developed through quantitative and qualitative methods, to essays and literature reviews. Of the research articles chosen by the student and faculty presenters over the first year, about one third were qualitative, one third quantitative, and one third theoretical pieces, essays, or literature reviews. A faculty member commented that "the articles presented stemmed from diverse viewpoints. This variation allowed the participants to engage in lively discussions that ranged from manuscript format to methodological issues."

The discussions that followed the presentation of the article were perceived as the most interesting part of the sessions. Many of the discussions gravitated towards the multiplicity of methodologies and the different possible interpretations of the data. Some of the discussions focused on the differences between quantitative and qualitative research designs. One of the students noted:

We are exposed to both [kinds of research]. The professors say, "I'm a quant person. I'm a qual person"... maybe there's something about [the research] that they like... but either way I am exposed to [the debate], whereas I might not be otherwise... it is important to be exposed to both kinds [of research] and to be critical of both kinds and say "look, there are problems with this study"...It depends on how you build it, on how you support it.

Some students were impressed with the freedom provided in the examination of the articles:

I liked the fact that the methodology [for the paper presented] was poor and we could really kind of tear it up ... that made me feel it was okay to critique these scholars, and to critique these professors you may even know... but in that scholarly debate, it is okay to find those things that need to be improved and it got me fired up - that our opinions are valued in getting to this level of scholarship.

The other commented:

You can get some dynamic discussion going on there. "Well, if they had done this as a quant study, this wouldn't have happened..." or just the opposite...so that's kind of neat. Sitting in these particular sessions have helped me put some of the things you learn in the classroom in perspective.

The journal club conversations helped graduate students witness the complex debate present in the field of education. Debates were modeled using research-centered arguments, and epistemological stances, and through these conversations students were exposed to and slowly engaged in discussions about research. Towards the end of the first year, some students were, however, still apprehensive to critique research: 
I'm not totally comfortable with that yet. I'm learning [about how to talk about methods] and that is one of the reasons that I chose the article to talk about. I see it as an opportunity to stretch my skills. I even had to come to the conclusion that this is how I think about research and get people's feedback like [the professors at the meeting] whose knowledge about research is much greater than mine.

These experiences suggest that the journal club was providing students with the opportunity to "stretch" their thinking by engaging in intellectual risk-taking. We perceived, however, that in order to encourage this type of risk in an open researchcentered debate, it had to be fostered in a safe and friendly environment, where professors were on equal grounds in the ownership of an intellectual space. From the students' and faculty perceptions, we learned that the research journal club is engaging the faculty and graduate students to current and diverse research methods and findings in educational leadership research, providing an open and safe environment for students and faculty to engage in intellectual risk-taking, and creating an increased sense of community around research.

\section{Findings: Journal Club Outcomes in the First Year of Implementation}

The journal club project was celebrated with a pizza lunch at the end of the academic year. The graduate students governing the sessions felt rewarded with the experience and were positively surprised with the faculty participation. A new governance group was to start in the next academic year, and the roles were again distributed among the students, with one of the students who participated in the last year chosen as the next journal club coordinator. As researchers, we reflected on our initial intention to investigate this signature pedagogy through the development of a journal club in the department. We perceived students as generating a new tradition in this university.

The use of graduate courses alone to engage graduate students and faculty in discussions of educational research methods was one of our early concerns. Confronting diverse and at times opposing epistemologies in courses seemed, in many instances, to be creating a negative atmosphere in which students struggled with the material, felt overly pressured, and reported disillusionment, confusion, and bewilderment (Lesko et al., 2008; Mertz, 2001; Young, 2001). In the research related to preparing educational researchers to date, while classroom experiences appear to expose and confront student perceptions of educational research and ways of knowing that they may value after the fact, they do not seem to provide the type of opportunity that could create a community of educational research practice. In a community of educational research practice, students and faculty can come together to engage in discussions around educational research in which intellectual risk-taking is valued. Most importantly, participants continuously return to the community for support, guidance, and collaboration (Golde, 2007a; Pallas, 2001; Shulman, 2005).

The students' participation led to meaning-making opportunities and the reification of their work. Evidence of such reification could be seen when students bridged their experiences from the journal club into their courses. A student commented that:

[In the journal club] there are a lot of different points of view. We may not always agree, but you have to listen and through listening you might pick-up something or put something in your notes that you will jot down. You can research and get some good ideas for what it is that you're doing, what you're studying... and I found it to be a big help in my classes and in the literature review I will develop for my dissertation studies.

Similarly, many of the faculty perceived the journal club as beneficial. We learned that some faculty members were recommending or even requiring students to attend the journal club as part of their course assignments. Most interestingly, it seemed that the journal club was creating a community of practice among faculty as well, as exemplified by one of the professors:

[The journal club] has been very useful in informing me about how to teach research methods. I have even used articles from the club in my research methods classes. The club is a great way to test articles and to get exposed to a wider array of articles for use in class.

The faculty was not necessarily able to perceive the journal club benefits in terms of students developing a community of practice, since they did not always attend consecutive meetings. One faculty member noted that "the journal club is one piece of a big puzzle towards creating an organizational culture of scholarly inquiry. It's not the end all, but it is a piece that is supportive of scholarly pursuits." Indeed, we were able to witness graduate students forming collaborative bonds with other students and faculty. These bonds would have occurred less frequently considering that students in the department of educational leadership are often practitioners employed full-time, with very little opportunities to meet with professors and other students in the department.

While we recognize that it is too early to evaluate the long-term benefits of the journal club in a college of education, and more specifically for students in educational leadership, the first year appears to be initiating and extending student research networks and conversations within and beyond the journal club, providing opportunities for students and professors to expand research agendas, and building practical aspects of a community of educational research practice. In the implementation of a signature pedagogy, we agree with Golde (2007a) that the activity is providing students with the opportunity to see "what counts" as knowledge in the field. In our study, the students were able to define "how knowledge is analyzed, criticized, accepted, or discarded" (Shulman, 2005, p. 56). We are hopeful that the students will continue to develop a tradition of a well-mastered habit to transform the feared process of learning research into an invigorating process of understanding, developing, criticizing, and applying research not only in their studies, but in the much needed improvement of schools.

\section{Implications}

Although the early indications appear to suggest that the journal club is an overall positive that aids in expanding the conversation and community around research in the department, responses from both the graduate students and the faculty point to two unresolved issues. First is the tenor of the conversations during the journal club, and how conversations differed based on the number of professors versus the number of graduate students attending the sessions. In journal club sessions held in the mornings, the ratio of faculty to graduate students was generally close to one-to-one as opposed to the afternoon sessions when 
faculty were less participative. When faculty members tended to dominate the discussions, it dampened the students' motivation to contribute during these sessions.

There were occasions in which the conversations at the journal club were somewhat one-sided, with faculty dominating the discussion from a research perspective while students related examples from their experiences in schools. While it could be said that student examples from their lived experiences could prove beneficial and show application of the research discussed, student comments of these conversations appeared to be mixed. The discussion may benefit from efforts to include more of the student's perspectives and their experiences as direct application of research

The second unresolved issue around the journal club is the question of access for part-time students. For part-time students especially, opportunities to participate in programs like the research journal club, held during regular working hours, were restricted. Interactions with faculty are known to be particularly difficult for these students (Militello, Murakami-Ramalho, \& Piert, in press). This appears to be consistent with our case of the implementation of a journal club. A faculty member stated the problem in the following way:

The journal club appears to be positively impacting the full-time students enrolled in the doctoral program. They are learning the culture of the academy, and this supports their socialization. Yet, I only see this handful of students benefitting. The majority of doctoral students who work full-time are unable to participate and therefore are missing out on this valuable opportunity.

Even though these implications affected the effectiveness of activities in graduate studies, we still perceive the research journal club as benefitting students. Communities of research practice and inquiry were at least modeled so that students could replicate these opportunities to examine research with other colleagues unable to attend the journal club, or even take the information outside of the university environment into other groups of professionals.

\section{Concluding Thoughts}

This study described the ongoing process of creating a research journal club with faculty and graduate students in a department of educational leadership. Through the journal club, the department of educational leadership in this university began the difficult task of preparing students to become skilled researchers and practitioners. We began to address the critiques in the preparation of educational leaders, especially in relation to the rigor, content, and relevancy of preparation programs, by providing researchoriented opportunities to initiate conversations between graduate students and faculty, and by establishing a space to model scholarly arguments and debate around research.

We wondered if the research journal club could be better incorporated into the current program in educational leadership both for masters and doctoral students. Volunteerism from faculty to supervise and participate in the journal club may not guarantee the effective establishment of this activity as a department tradition to benefit students who needed it the most - students who have little time allocated to developing research due to their full-time jobs.
The faculty advisors encountered difficulties encouraging faculty and students to be involved, especially because of the same time limitations. Nevertheless, as researchers observing the demonstrated benefits of the research journal club, it is our hope that we continue to see this college pursue the continued implementation of the journal club. Hopefully, other universities genuinely concerned with the quality of educators being prepared around the nation will be more invested in considering the development of research-oriented habits among studentpractitioners, engaging them in increased formal and semi-formal research-oriented discussions, and bringing together faculty and students to encourage a community of practice centered on high quality research and application.

\section{RECOMMENDED CITATION FORMAT}

Bowers, A.J., Murakami-Ramalho, E. (2010) The Research Journal Club: Pedagogy of Research in the Preparation of Students in Educational Leadership. Journal of Research on Leadership Education, 5(10), 335-356.

doi:10.1177/194277511000501001

\section{REFERENCES}

Alguire, P. C. (1998). A review of journal clubs in postgraduate medical education. Journal of General Internal Medicine, $13,347-353$

Berliner, D. C. (2006). Toward a future as rich as our past. In C. M. Golde \& G. E. Walker (Eds.), Envisioning the future of doctoral education: Preparing stewards of the discipline (pp. 268-289). San Francisco, CA: Jossey-Bass.

Black, W. R., \& Murtadha, K. (2007). Toward a signature pedagogy in educational leadership preparation and program assessment. Journal of Research on Leadership Education, 2(1).

The Carnegie Foundation for the Advancement of Teaching (2007). Standards listings of institutions by classification. Retrieved October 12, 2008, from http://www.carnegiefoundation.org/classifications/index.asp ?key $=783$

Creswell, J. W. (2005). Educational research: Planning, conducting, and evaluating quantitative and qualitative research $\left(2^{\text {nd }}\right.$ ed.). Upper Saddle River, NJ: Pearson.

Creswell, J. W., Hanson, W. E., Clark, V. L. P., \& Morales, A. (2007). Qualitative research designs: Selection and implementation. The Counseling Psychologist, 35(2), 236264.

Cronon, W. (2006). Getting ready to do history. In C. M. Golde \& G. E. Walker (Eds.), Envisioning the future of doctoral education: Preparing stewards of the discipline. Carnegie essays on the doctorate (pp. 327-349). San Francisco: Jossey-Bass.

Eckardt, N. (2007, November 8). The prevalence of qualitative methodology at AERA's annual meeting and the potential consequences. Teachers College Record, ID Number: 14741. Retrieved April 11, 2010, , from http://www.tcrecord.org

Ercikan, K., \& Roth, W. M. (2006). What good is polarizing research into qualitative and quantitative? Educational Researcher, 35(5), 14-23.

Golde, C. M. (2007a). Signature pedagogies in doctoral education: Are they adaptable for the preparation of education researchers? Educational Researcher, 36(6), 344351.

Golde, C. M. (2007b, month). Teaching students to ask good research questions. Paper presented at the annual meeting of 
the Association for the Study of Higher Education, Louisville, KY.

Golde, C. M., \& Walker, G. E. (2006). Envisioning the future of doctoral education: Preparing stewards of the discipline. San Francisco, CA: Jossey-Bass.

Hess, F. M., \& Kelly, A. P. (2005). Learning to lead? What gets taught in principal preparation programs. Cambridge, MA: The Program on Education Policy and Governance.

Lave, J., \& Wenger, E. (1991). Situated learning: Legitimate peripheral participation. Cambridge, UK: Cambridge University Press.

Lesko, N., Simmons, J. A., Quarshie, A., \& Newton, N. (2008). The pedagogy of monsters: Scary disturbances in a doctoral research preparation course. Teachers College Record, 110(8), 1541-1573.

Levine, A. (2005). Educating school leaders. New York: Education Schools Project.

Merriam, S. B. (2002). Qualitative research in practice: Examples for discussion and analysis. San Francisco, CA: Jossey-Bass.

Mertz, M. H. (2001). Intellectual border crossing in graduate education: A report from the field. Educational Researcher, 30(5), 12-18.

Miles M. B., \& Huberman A. M. (1994). Qualitative data analysis: An expanded sourcebook. Thousand Oaks, CA: SAGE Publications.

Murakami-Ramalho, E., Militello, M., \& Piert, J. (2011). A view from within: How doctoral students in educational administration develop research knowledge and identity. Studies in Higher Education. 38(3), 1-16. $n$.

Murphy, J. (2006). Some thoughts on rethinking the pre-service education of school leaders. Journal of Research on Leadership Education, 1(1).
Page, R. N. (2001). Reshaping graduate preparation in educational research methods: One school's experience. Educational Researcher, 30(5), 19-25.

Pallas, A. M. (2001). Preparing education doctoral students for epistemological diversity. Educational Researcher, 30(5), 611.

Shulman, L. S. (2005). Signature pedagogies in the professions. Daedalus, 134(3), 52-59.

Silverberg, R. P., \& Kottkamp, R. B. (2006). Language matters. Journal of Research on Leadership Education, 1(1).

Stake, R. E. (1995). The art of case study research. Thousand Oaks, CA: Sage.

Stake, R. E. (2005). Qualitative case studies. In N. K. Denzin \& Y. S. Lincoln (Eds.), Handbook of qualitative research (3rd ed., pp. 443-466). Thousand Oaks, CA: Sage.

Tierney, W. G. (2006). The changing nature of organizational leadership and culture in academic work. Journal of Research on Leadership Education, 1(1).

Walker, G. E., Golde, C. M., Jones, L., Bueschel, A. C., \& Hutchings, P. (2008). The formation of scholars: Rethinking doctoral education for the twenty-first century. San Francisco: Jossey-Bass.

Wenger, E. (1998). Communities of practice: Learning, meaning and identity. New York: Cambridge University Press.

Yin, R. K. (2003). Case study research: Design and methods (3rd ed.). Thousand Oaks: Sage.

Young, L. J. (2001). Border crossings and other journeys: Reenvisioning the doctoral preparation of education researchers. Educational Researcher, 30(5), 3-5.

Young, M. D., Orr, M. T., Crow, G., \& Ogawa, R. T. (2005). Commentary: An educative look at 'educating school leaders.' School Leadership News, 11 (addendum), 1-7. 